\title{
DEVELOPMENT AND APPLICATION OF A HIGHLY SENSITIVE PNA CLAMP PCR ASSAY FOR DETECTION OF NRAS MUTATIONS IN MELANOMA USING TISSUE AND CFDNA
}

\author{
Reger R.Mikaeel ${ }^{* 1}$, Isavella Evangelou, , Mr. Joshua Bilbie, \\ DR. JAMES Howard Pringle and DR. GERALD SALDANHA ${ }^{2}$ \\ ${ }^{1}$ Dept. Of Biology, College of Science, University of Duhok, Kurdistan Region-Iraq \\ ${ }^{2}$ Dept. of cancer Studies and Molecular Medicine, University of Leicester-England
}

(Received: November 2, 2017; Accepted for Publication: March 6, 2018)

\begin{abstract}
Melanoma is known to be one of the common cutaneous cancers worldwide. NRAS mutations are found in $15 \%-20 \%$ of melanomas. Non-NRAS-mutant subset of melanoma is less aggressive and associated with higher outcomes in comparison to NRAS- mutant melanoma. New treatment methods for this subset might be developed with improved understanding of NRAS-mutant melanoma. Therefore, a highly sensitive technique for detection of NRAS mutation in melanoma is imperative. The aims of this research were to develop a highly sensitive PCR assay to detect low tumour cell percentage in formalin fixed paraffin embedded (FFPE) tissue and plasma. The assay was developed on stable cell lines containing NRAS (codon 61) mutations. Peptide nucelic acide (PNA) Clamp PCR was used for the selective amplification of DNA target sequences. Total DNA was extracted from 48 FFPE tissues and 20 blood plasma (14 matched) stage II-IV tumours and screened for NRAS mutations. PNA Clamp PCR on FFPE tissue showed $25 \%(n=12)$ NRAS mutant of which p.Q61R c.182A $>$ G was the most frequent. Sample cases were independently tested. For NRAS Circulating cell free DNA (cfDNA) analysis only one case was mutated. This demonstrates an innovative and highly sensitive technique for the detection of the common driver mutations in melanoma using exceptionally low tumour burden samples, representing a useful tool for future research and clinical application.
\end{abstract}

KEYWORDS: Melanoma, NRAS, Quantitative PCR, FFPE tissue, cfDNA

\section{INTRODUCTION}

T The therapeutic management of disseminated melanoma has been a considerably shifted throughout the recent five years. The long and short term disease control might be a reality after the clinical success of immunotherapy and BRAF-targeted therapy with very high responders (Jakob et al, 2012). Although NRAS and BRAF co-mutations are not mutually exclusive, the sole finding of double mutated cells in a non-responding cancer is not enough to determine follow-up treatment, and combinational therapy that target various pathways will be essential (Posh and Susana, 2003). Some specific driver mutations have been described and each of them has a very wellknown unique genetic and clinical features. BRAF, NRAS and CKIT are the most commonly described and they might serve as potential therapeutic targets. Despite the fact that more attention has been focused upon $B R A F$-mutant melanoma, the first identified melanoma oncogene was NRAS (Omholt et al, 2003). The RAS family comprises
NRAS (human neuroblastoma), KRAS (Kirsten rat sarcoma viral oncogene homolog) and HRAS (Harvey rat sarcoma viral oncogene homolog). RAS proteins are small GTPases which can either have an inactive guanosine diphosphate (GDP) bound or an active guanosine triphosphate (GTP) bound form. RAS can activate PI3K-AKT-mTOR pathway, associated with cell survival, and the RAS-RAF-MEKERK pathway, associated with cell proliferation (Christine Lovly, et al., 2014). NRAS is one of the most common somatic mutations found in melanoma in $\sim 17 \%$ of melanoma cases and currently there is no targeted therapy. A trial with farnesyltransferase inhibitors (FTIs) on metastatic melanoma patients has been done but with no response from the patients therefore the trial was terminated (Flaherty K. et al., 2012). Most NRAS mutations associated with melanoma occur in codon 61 (Swick J. et al., 2012). Mutations result in activation of NRAS signalling pathway. The mutations present in codon 61 are NRAS c.181C $>\mathrm{G}$ (Q61E), NRAS c.181C $>$ A (Q61K), NRAS c.182A $>$ T (Q61L), NRAS c.182A $>C$ (Q61P), NRAS c.182A $>$ G 
(Q61R), NRAS c.182 A>T (Q61L), NRAS c.182 A>G (Q61R), NRAS c.182, NRAS c. $183 \mathrm{~A}>\mathrm{C} \quad(\mathrm{Q} 61 \mathrm{H})$ and NRAS c.183A $>\mathrm{T}$ (Q61H) (Cancer.sanger.ac.uk, 2014). KRAS has been found in only $2 \%$ of melanomas but has an important role in other cancers such as pancreatic and colon and HRAS is present in $1 \%$ of melanomas (Swick J. et al., 2012). The patients harbouring BRAF mutations are found to be younger than patients with NRAS mutations and have less levels of mitosis than NRAS-mutant melanomas. Furthermore, NRAS mutant melanoma is reported to have a thicker primary tumours and a lower rate of ulceration in comparison to the BRAF mutant melanomas. Several studies have found that NRAS mutations are associated with improved overall survival (OS) in comparison to the patients with BRAF mutations.

It is worth mentioning that improved understanding of molecular and genetic basis of melanoma has revolutionized treatment options for this cancer. There are various methods for the detection of mutations in melanoma such as COBAS4800 BRAF V600 test, Sanger sequencing, mutant allele-specific PCR, PNA clamp real-time PCR and pyrosequencing (Lyon E. et al., 2009). However, in spite of these advances, the detection of driver mutations in melanoma remains challenging and new sensitive methods for detection of mutations and cost effective should be used. The need for a more sensitive and specific method for detecting mutations lead to the development and application of PNA Clamp PCR. Peptide nucelic acide (PNA), which is an artificially synthesized polymer, is capable of binding DNA in a sequence specific manner. It has been used in experimental therapeutics, diagnostics, genetic research and many other biomedical applications (Chen et al. 2004). PNAs are DNA mimic, in which the negatively charged deoxyribose phosphate backbone is replaced by an uncharged pseudo-peptide backbone $\mathrm{N}$-(2-aminoethyl) glycine units linked by peptide bonds (Skronski et al. 2011). PNA molecules are most commonly used as probes of complementary DNA sequences. The PNA clamp is designed to effectively target the point mutations and to block wild type DNA from competing in the $\mathrm{PCR}$ as a template.

The presence of cell-free DNA (cfDNA) in human blood was first described in 1948, by Mandel and Métais. However, its importance was not recognized until fragments of a mutated RAS gene were detected in the blood of cancer patients in 1994 (Schwarzenbach et al. 2011). The release of cfDNA into the blood is found to be associated with necrosis and apoptosis of cancer cells in the tumour microenvironment. Moreover, secretion has also considered as a possible source of cfDNA. Apoptotic and necrotic cells are usually phagocytosed by scavenger cells such as macrophages which in turn can secret digested DNA in to the tissue environment. cfDNA is composed of both mitochondrial DNA (mDNA) and genomic DNA (gDNA) (García-Olmo et al. 2010). However, whereas mDNA circulates in nonparticle associated and particle associated forms, gDNA usually circulates in plasma in cell free form. cfDNA can be used to examine cancer specific gene mutations such as TP53 and KRAS which contribute to cancer progression and are frequently mutated in many tumour types (Spindler et al. 2012). Moreover, clinically relevant mutations in adenomatous polyposis coli (APC), epidermal growth factor (EGFR) and BRAF have now been studied in cfDNA. Several drugs that target EGFR, KRAS, BRAF and TP53 are used in clinical trials and the mutation status of the patient's tumour needs to be identified in order to predict response to treatment (Schwarzenbach et al. 2011). It is found that cfDNA can provide a unique opportunity to repeatedly monitor patients during treatment. However, assay specificity and sensitivity has been the major problem of this approach because wild type sequences usually interfere with the cfDNA mutation assays (Schwarzenbach et al. 2011).

The aims and objectives of this project were to develop a highly sensitive assay which can detect a low tumour cell percentage of $0.1 \%$ in NRAS codon $61 \quad$ ((c.181C>A (P.Q61K), C.182A $>$ T (P.Q61L), C.182A $>$ G (P.Q61R)) in cfDNA and FFPE tissues. PNA Clamp QUASAqPCR were used for the selective amplification of DNA target sequences that differ by a single base pair. The sensitivity of the assay was assessed by a model experiment of whole genomic DNA with mutant DNA and the specificity by detecting all ranges of mutation frequencies.

\section{MATERIALS AND METHODS Cell lines}

A variety of cell lines were used in the project such as SK-MEL-2, HT-1080, IPC-298 and RD. All cell lines except RD were obtained from Dr. Pringle's lab and cultured appropriately. RD cell line was obtained from European Collection of Cell Cultures (ECACC, http://www.pheculturecollections.org.uk/collecti ons/ecacc.aspx) Extensive information about the cell lines is shown in table 1 . 
Table (1): Cell line information

\begin{tabular}{cccc}
\hline Cell line & Mutation & Genotype & Description \\
\hline SK-MEL-2 & NRAS p.Q61R $(\mathrm{c} .182 \mathrm{~A}>\mathrm{G})$, & Heterozygous & $\begin{array}{c}\text { melanoma cell line metastasis on } \\
\text { skin of upper leg }\end{array}$ \\
\hline HT-1080 & NRAS p.Q61K $(\mathrm{c} .181 \mathrm{C}>\mathrm{A})$ & Heterozygous & $\begin{array}{c}\text { melanoma cell line derived from soft } \\
\text { and fibrous tissue }\end{array}$ \\
\hline IPC-298 & NRAS p.Q61L (c.182A $>\mathrm{T})$ & Heterozygous & $\begin{array}{c}\text { melanoma cell line derived from the } \\
\text { skin }\end{array}$ \\
\hline RD & NRAS p.Q61R $(\mathrm{c} .183 \mathrm{~A}>\mathrm{T})$ & Heterozygous & $\begin{array}{c}\text { rhabdomyosarcoma and embryonal } \\
\text { cell line derived from soft tissue or } \\
\text { striated muscle }\end{array}$ \\
\hline
\end{tabular}

\section{Melanoma samples}

A number of 48 formalin fix paraffin embedded (FFPE) tissue blocks and 20 blood plasma (14 matched with tissue) collected from 2008-2014; were obtained with ethical approval from pathology archives at Leicester Royal Infirmary and were tested for NRAS Q61K, Q61R, Q61L and $\mathrm{Q} 61 \mathrm{H}$ by PNA Clamp quantitative allele specific amplification (QUASA) PCR respectively. All samples were taken from melanoma patients and were tested for histological and clinico-pathological features. The clinic-pathological features of the melanoma samples are shown in table 2 . Melanoma stages for patients with blood sample ranged from II-IV (IIC: $n=1$, IIIB: $n=1$, IIIC: 1 , IV: $\quad \mathrm{n}=15, \quad$ Unknown: $\mathrm{n}=2$ )

Table (2): Clinic-pathological features of melanoma cases

\begin{tabular}{ll}
\hline Gender & 35 \\
\hline Male & 19 \\
\hline Female & \\
\hline Age (median age 71 years) & 35 \\
\hline$\leq 71$ years & 19 \\
\hline$>71$ years & 33 \\
\hline & 11 \\
\hline Primary & 4 \\
\hline Secondary & \\
\hline Unknown & 22 \\
\hline & 11 \\
\hline Location & 2 \\
\hline Torso & 1 \\
\hline Limbs & 22 \\
\hline Head and neck & \\
\hline Acral melanoma & \\
\hline Mucosal melanoma & \\
\hline
\end{tabular}


Unknown 4

NRAS mutation analysis

Primer, probe and PNA design for QUASAqPCR

For NRAS gene, primer designing tool (Primer Blast) was used. Primer Blast which was developed at National Centre for Biotechnology Information (NCBI) is used to make primers specific to the target DNA sequence. It uses Primer3 (Primer3.ut.ee, 2014) to design PCR primers and then uses Basic Local Alignment Search Tool (BLAST) and global alignment algorithm to screen primers against user-selected database in order to avoid primer pairs that can cause non-specific amplifications (Ncbi.nlm.nih.gov, 2014). The designed forward and reverse primers amplify NRAS fragment in exon 3 codon 61.The resulting amplicon had a size of 84 base pairs (bp). The forward primer started at position 7947 and finished at 7969 (23 bp) and the reverse primer started at position 8011 and finished at position 8031 (21 bp). Probes were designed by using the same software. Four probes were designed; of which one probe was away from the mutation, one was allele-specific (wild-type probe) and the other two were allele- mutant specific probes (MA and MTG). The probes were 14bp long except the probe away from mutation which was 16bp long. Primer express 3.0 software (Applied
Biosystems, Cheshire, UK) was used to check the properties of the primers and the probes which are presented in table 3 .

NRAS c.181 C>A, c.182 A>G, c.182 A>T, c. $182 \mathrm{~A}>\mathrm{C} \quad$ c. $183 \mathrm{~A}>\mathrm{T}$ and $\quad$ c. $183 \mathrm{~A}>\mathrm{C}$ were distinguished from wild-type samples by mutation specific tag primers. Tag primers are short sequences with a number of oligonucleotides attached to the 5' end terminal. All tag primers are forward primers and are 21 bp long (Table 4). All the primers were synthesised by Sigma (Sigma Aldrich, Dorset, UK) and the probes were synthesised by Applied Biosystems (Chesire, UK). In addition to tag primers, a peptide nucleic acid (PNA) was designed. PNA's are artificially synthesized polymers similar to DNA. The designed PNA was 18bp long and was synthesised by Eurogentec. According to the manufacturer's guideline, PNA oligomer should be able to form duplexes in either orientation, has a length between 12-18 bases, have 7 purines in a length of 10 bases and the mutation base is better to be in the middle. In addition to the manufacturer's guidelines, an online PNA design tool (http://pnabio.com/support/PNA Tool.html) was used (Table 4). 
Table (3): NRAS codon 61 PNA Clamp QUASAqPCR primers and probes and PNA.

\begin{tabular}{|c|c|c|c|c|}
\hline & Sequence & $\mathrm{Tm}$ & $\% \mathrm{GC}$ & Length \\
\hline Forward primer & GGTGAAACCTGTTTGTTGGACAT & 58.8 & 43 & 23 \\
\hline Reverse primer & CGCCTGTCCTCATGTATTGGT & 58.5 & 52 & 21 \\
\hline Wild type primer & GCGACGGATACAGCTGGACAA & 69.5 & 57.1 & 21 \\
\hline c. $181 \mathrm{C}>\mathrm{A}(\mathrm{p} . \mathrm{Q} 61 \mathrm{~K})$ & GAGCGACGGATACAGCTGGA音 & 68.6 & 57.1 & 21 \\
\hline c. $182 \mathrm{~A}>\mathrm{T}$ (p.Q61L) & GAGCGACGATACAGCTGGACT & 65.7 & 57.1 & 21 \\
\hline c. $182 A>G(p . Q 61 R)$ & GAGCGACGATACAGCTGGACE & 69.3 & 61.9 & 21 \\
\hline c.183A>T (p.Q61H) & GAGCGAGATACAGCTGGACAT & 63.3 & 52.3 & 21 \\
\hline Probe WT & VIC-CAGCTGGACAAGAA-MGB & 66 & 50 & 14 \\
\hline Probe MA & FAM-CAGCTGGAAAAGAA-MGB & 68 & 43 & 14 \\
\hline Probe MTG & NED-CAGCTGGACK*AGAA-MGB & 64 & 57 & 14 \\
\hline PROBE & $\begin{array}{l}\text { FAM-TACAGTGCCATGAGAG- } \\
\text { MGB }\end{array}$ & 66 & 50 & 16 \\
\hline PNA & ATACAGCTGGACAAGAAG & 70 & 44 & 18 \\
\hline *: Ambiguous codon (eit & ed: TAG sequence, blue: mutation, & $\rightarrow$ & & \\
\hline
\end{tabular}

Table (4): PNA properties according to (http://pnabio.com/support/PNA Tool.html)

\begin{tabular}{ll}
\hline Complete Sequence & ATACAGCTGGACAAGAAG \\
\hline Tm at $2 \mathrm{uM}^{\circ}$ & $66.34{ }^{\circ} \mathrm{C}$ \\
\hline Base Count & 18 \\
\hline Base Composition & $\mathrm{A}=8(44.4 \%) \mathrm{T}=2(11.1 \%)$ \\
& $\mathrm{G}=5(27.8 \%) \mathrm{C}=3(16.7 \%)$ \\
\hline Purines (\%) & $72.2 \%$ \\
\hline GC Content & $44.4 \%$ \\
\hline PNA Chemical Formula & C195H239N115O48 \\
\hline Molecular Weight (including linker and peptide) & 4961.7 \\
\hline PNA Sense Sequence (5' to 3') & ATACAGCTGGACAAGAAG \\
\hline Reverse Complementary Sequence (5' to 3') & CTTCTTGTCCAGCTGTAT \\
\hline Comment & Good \\
\hline Self-complementarity & ATACAGCTGGACAAGAAG \\
\hline
\end{tabular}

\section{Cell culture}

The cell lines that were cultured were SKMEL-2, SK-MEL-30, RPMI-7951 and IPC-298. At first, cells were resuscitated from liquid nitrogen and defrosted at $37^{\circ} \mathrm{C}$. The cells were transferred to a sterile falcon tube containing 10 $\mathrm{mL}$ pre-warmed Roswell Park Memorial
Institute - 1640 (RPMI-1640) with $10 \%$ foetal calf serum (FCS) (Sera-lab) and centrifuged. Media was removed and the cell pellet was resuspended in pre-warmed RPMI-1640 media, transferred to a $25 \mathrm{~mL}$ dewar flask (T-25) and incubated overnight in $5 \% \quad \mathrm{CO}_{2}$ atmosphere. Growth media was removed and the cells 
monolayer was washed twice with pre-warmed $\left(37^{\circ} \mathrm{C}\right)$ phosphate buffered saline (PBS) (Lonza). Then, $5 \mathrm{~mL}$ of pre-warmed trypsin with Ethylenediaminetetraacetic acid (EDTA) solution were added on the cells. Cells were then centrifuged with an equal amount of growth medium (the growth medium neutralised the trypsin). Cell pellets were re-suspended in prewarmed growth media and then transferred to $75 \mathrm{~mL}$ dewar flasks (T-75) and allowed to grow until they reach confluence of $80-90 \%$.

For DNA extraction, the same procedure was followed but cells after re-suspension they were divided into $1.5 \mathrm{~mL}$ tubes and centrifuged at $14000 \mathrm{rpm}$ for 5 minutes. A pellet was formed and the growth media was discarded. Cell pellets were stored at $-80^{\circ} \mathrm{C}$ for DNA extraction.

\section{DNA extraction from cell lines}

DNA was extracted from SK-MEL-2, SKMEL-30, IPC-298 and RPMI-7951 cell lines. Cell pellets of each cell line were re-suspended in $250 \mu \mathrm{l}$ of $0.05 \mathrm{M}$ Tris $\mathrm{pH} 8 / 0.1 \%$ SDS. Proteinase kinase $(\mathrm{PK})$ was then added. The mixture was then incubated at $37^{\circ} \mathrm{C}$ for 1 hour. An equal amount of phenol/chloroform/IAA was then added to the tube and centrifuged. The top layer (aqueous) of the solution was added to a clean $1.5 \mathrm{~mL}$ tube without disturbing the interface, and an equal amount of phenol/chloroform/IAA was added and centrifuged at $14000 \mathrm{rpm}$. The top layer was again transferred to a clean tube. Cold ethanol ($20^{\circ} \mathrm{C}$ ) (X3 times the starting volume; $\left.750 \mu \mathrm{l}\right)$ and $1 \mathrm{M}$ sodium chloride $(\mathrm{NaCl})(1 / 10$ of starting volume; $2.5 \mu \mathrm{l}$ ) were added to the mixture and left at $-20^{\circ} \mathrm{C}$ for 30 minutes and microfuged at $14000 \mathrm{rpm}$ for 15 minutes at $4^{\circ} \mathrm{C}$. Following, the pellet was washed with ethanol and centrifuged at $14000 \mathrm{rpm}$ for 15 minutes at $4^{\circ} \mathrm{C}$ and the ethanol was left to air dry. Finally the pellet was re-suspended in $300 \mu$ l of ultrapure sterile water and stored at $4^{\circ} \mathrm{C}$.

\section{DNA extraction from FFPE tissue}

FFPE tissues were prepared by the histology laboratory of Robert Kilpatrick Clinical Sciences Building and the DNA was extracted using the QIAamp DNA FFPE tissue kit (Qiagen, Hilden, Germany; cat.no: 56404). Slides were incubated at $65^{\circ} \mathrm{C}$ and then they were de-waxed and rehydrated in xylene (2X3 minutes), 99\% (2X1 minute) and 95\% (1 minute) industrial methylated spirits (IMS). 200 $\mu \mathrm{l}$ of ATL buffer were used to scrape the sections and $10 \mu \mathrm{l}$ of PK recombinant, PCR Grade (Roche diagnostics) $(10 \mathrm{mg} / \mathrm{mL})$ were added and incubated at $56^{\circ} \mathrm{C}$ for up to 4 days. PK was added at least once during this period
(2.5 $\mu \mathrm{l}) .200 \mu \mathrm{l}$ AL buffer were added in each tube, centrifuged and transferred to $0.5 \mathrm{~mL}$ tubes. Samples were heated at $70^{\circ} \mathrm{C}$ in DNA thermal cycler and transferred to $1.5 \mathrm{~mL}$ tubes. $200 \mu \mathrm{l}$ of absolute ethanol were added and centrifuged. Samples were then applied on QIAamp columns and centrifuged at $8000 \mathrm{rpm}$ for 1 minute. Columns were then re-placed in a new collection tube and $500 \mu \mathrm{l}$ buffer AW1 were added and centrifuged again as before. 500 $\mu 1$ of buffer AW2 were added and centrifuged at $14000 \mathrm{rpm}$ for 3 minutes. Then, $35 \mu \mathrm{l}$ buffer AE were added and left for 5 minutes before centrifuging the samples at $8000 \mathrm{rpm}$ for 1 minute. Elution of DNA was transferred to a new tube and stored at $4^{\circ} \mathrm{C}$.

\section{cfDNA extraction from blood plasma}

Blood samples were obtained from patients of Leicester Royal Infirmary Hospital. Circulating cell-free (cfDNA) was extracted from blood plasma using QIAamp Circulating Nucleic acid kit (Qiagen, Hilden, Germany). Plasma samples $(1 \mathrm{~mL})$ were thawed and centrifuged and $100 \mu \mathrm{l} \mathrm{PK}$ was added to $15 \mathrm{~mL}$ falcon tubes and $1 \mathrm{~mL}$ of plasma supernatant was added. $0.8 \mu \mathrm{l}$ of ACL buffer were added in the falcon tube and incubated at $60^{\circ} \mathrm{C}$ for 30 minutes. An additional $1.8 \mu \mathrm{l}$ of ACB buffer were added and incubated on ice for 5 minutes. $680 \mu \mathrm{l}$ of the mixture were added to the QIAamp columns each time and centrifuged at $8000 \mathrm{rpm}$ for 1 minute until all the mixture was centrifuged (6 times). Then, the columns were transferred to a new collection tubes and $600 \mu \mathrm{l}$ of ACW1 buffer were added and centrifuged. The same procedure was repeated for buffer ACW2 $(700 \mu \mathrm{l})$ centrifuged at $14000 \mathrm{rpm}$ for 3 minutes. Columns were then transferred to delidded tubes and incubated at $56^{\circ} \mathrm{C}$ for 10 minutes. Columns were transferred to low-bind tubes (Eppendorf, Germany) and $50 \mu 1$ of AVE buffer were applied and incubated at RT for 3 minutes. Tubes were then centrifuged at 14000 rpm for 1 minute. Elution of cfDNA was stored at $4^{\circ} \mathrm{C}$.

Cell lines and DNA samples from melanoma cases were diluted appropriately in sterile UP water to have a final concentration of $10 \mathrm{ng} / 3 \mu \mathrm{l}$. The concentration of the samples was measured using Nanodrop spectrophotometer (ND-1000; Lab Tech International).

\section{Quantitative Real time PCR}

Quantitative real-time polymerase chain reaction (qPCR) for BRAF and NRAS genes was performed by adding a final volume of 10 $\mu \mathrm{l}$ of reaction in each well of 96-well plate. QUASAqPCR and ASLNAqPCR were 
completed by using $7 \mu$ l of mastermix which included $5 \mu \mathrm{l}$ of TaqMan Genotyping Master Mix (Applied Biosystems, cat.no: 4371355, Cheshire, UK), $0.2 \mu \mathrm{l}$ of appropriate forward primer, reverse primer, probe and PNA and the remaining amount of $\mu \mathrm{l}$ was used for sterile UP water. An additional $3 \mu \mathrm{l}(10 \mathrm{ng} / 3 \mu \mathrm{l})$ of DNA was added to each well to give a final amount of $10 \mu \mathrm{l}$. The positive controls that were used for qPCR were human genomic DNA (HGDNA) and cell lines and for negative control no template control/sterile UP water (NTC) was used. All the samples were loaded in duplicates. PCR was performed by using the standard mode running ( $\sim 2$ hours) on a StepOne Plus Applied Biosystems Real-time PCR (Applied Biosystems, USA) machine for 50 cycles and the thermocycling conditions that were used for QUASAqPCR are shown in Table 5.

Table 5: PCR conditions for QUASAqPCR QUASAqPCR (Touchdown method)

\begin{tabular}{ccccc}
\hline Temperature & Time & Cycles & Starting cycle & Stage \\
\hline $95^{\circ} \mathrm{C}$ & $10^{\prime}$ & 1 & 1 & Holding \\
\hline $95^{\circ} \mathrm{C}$ & $15^{\prime \prime}$ & 10 & 2 & Cycling (Denaturation) \\
\hline $69^{\circ} \mathrm{C}\left(-1^{\circ} \mathrm{C}\right.$ each cycle) & $1^{\prime}$ & 10 & 2 & Cycling (Annealing) \\
& & & & \\
\hline $95^{\circ} \mathrm{C}$ & $15^{\prime \prime}$ & 40 & 12 & Cycling (Denaturation) \\
\hline $62^{\circ} \mathrm{C}$ & $11^{\prime}$ & 40 & 12 & Cycling (Annealing) \\
\hline
\end{tabular}

\subsubsection{NRAS QUASA PNA Clamp PCR}

QUASAqPCR PNA Clamp assay was used to distinguish NRAS codon 61 mutant samples from wild type based on the base variations. The forward primers had an extra sequence of bases (tag) attached to their 5' end which was not complementary with the amplified allele. The last base of the forward primers was the same as the matching allele sequence and allowed the extension of the primers. In addition the PNA added in the assay was used to block the wild type amplification and allow the mutant.

\section{$\mathrm{Ct}$ and $\Delta \mathrm{Ct}$}

Quantitative PCR can define how much of the target sequence or gene is in a sample. If the reaction is positive, a fluorescent signal will be produced. The cycle threshold $(\mathrm{Ct})$ is the amount of cycles needed for the signal to be produced. If the amount of target nucleic acid, in our case DNA, is low the $\mathrm{Ct}$ value will be higher and vice versa. For a qPCR of 40 cycles the following rules define the amount of DNA in the samples. If:

a) Cts < 29: strong positive reactions, large amount of DNA in the sample b) Cts of 30-37: are positive reactions, moderate amounts of DNA in the sample

c) Cts of 38-40: are weak reactions, minimal amounts of DNA which can occur by contamination.

However, we used 50 cycles as we were using touchdown (TD) method that increases the number of cycles by 10-15. TD method was used to increase the specificity and sensitivity of PCR amplification. The starting annealing temperature for the first cycle phase was higher than primers $\mathrm{Tm}$ by $10^{\circ} \mathrm{C}\left(69^{\circ} \mathrm{C}\right)$ and then decreased by $1{ }^{\circ} \mathrm{C}$ every cycle until it reached the primers Tm (Kramer and Coen, 2001).

At the end of each reaction, the $\Delta \mathrm{Ct}$ of each sample was calculated by subtracting the wildtype $\mathrm{Ct}$ mean from the mutant $\mathrm{Ct}$ mean. $(\Delta \mathrm{Ct}=$ Mutant Ct mean - Wild type Ct mean)

\section{Statistical analysis}

Microsoft Excel (2013) and GraphPad Prism version 6 (GraphPad software, California, United States) software were used for statistical analysis. Microsoft Excel software was used to plot the analytical sensitivity graphs (ratio of mutated DNA against $\mathrm{Ct}$ mean) and One-way analysis of variance (ANOVA) followed by a non-parametric multiple comparison analysis Tukey's test were carried out to compare the ratio of mutated DNA to WT (control) DNA. If 
$p$ value was $\leq 0.05$, the results were statistically significant and if the $p$ value was $\geq 0.05$ results were non-significant.

\section{RESULTS}

\section{Specificity of PNA for PNA Clamp QUASAqPCR}

In order to validate the PNA, wild-type primer was checked with the cell lines in the absence of PNA and allele specific mutant primers were checked with the cell lines in the presence of PNA. HGDNA with wild-type primer has a $\mathrm{Ct}$ of 28 cycles and with mutant primer +PNA is completely suppressed (no amplification) (Figure 1A). HT-1080 with wildtype primer has a $\mathrm{Ct}$ of 36 cycles and with mutant primer +PNA has a $\mathrm{Ct}$ of 32 cycles; there is a difference of 4 cycles when the PNA is present (Figure 1B).
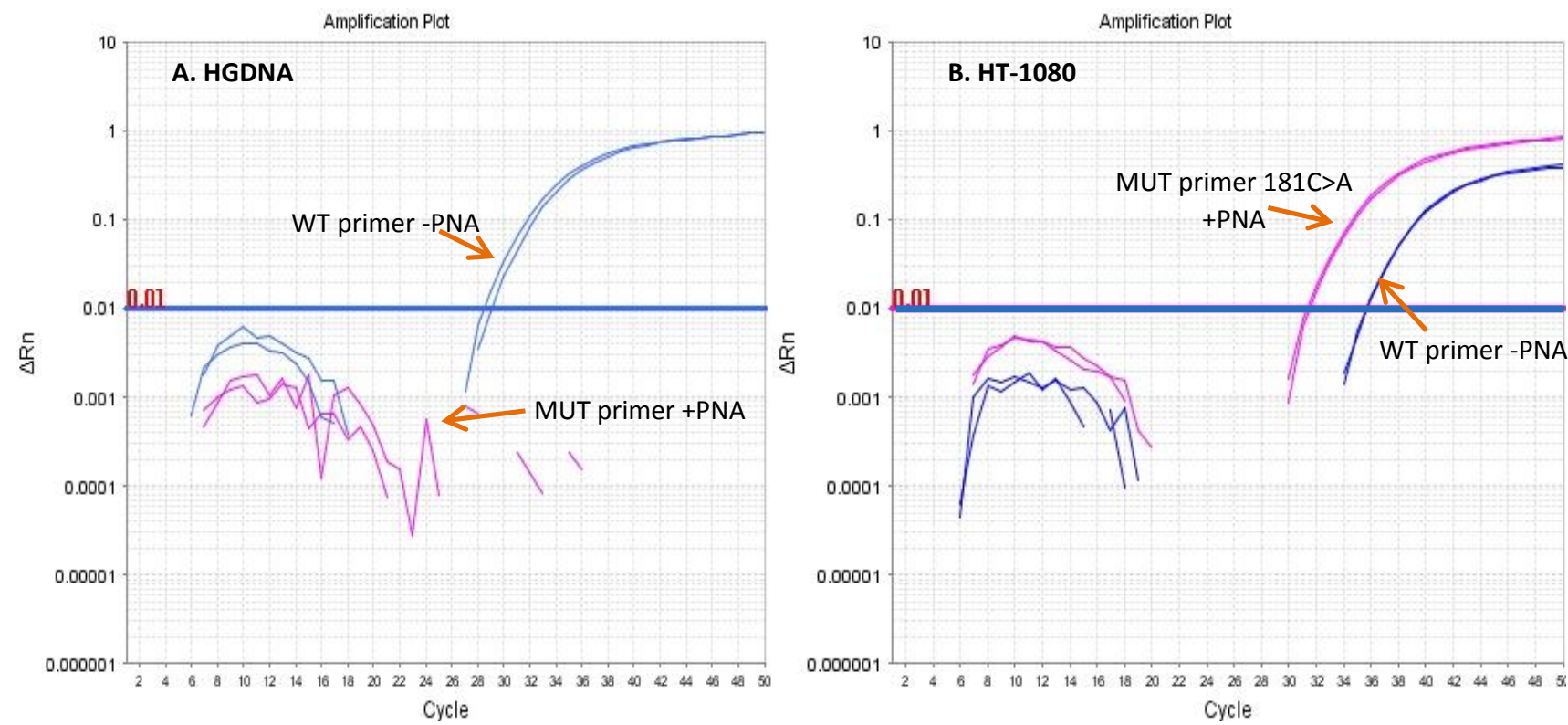

Fig. (1): Specificity of PNA for PNA Clamp QUASAqPCR. Amplification plot of HGDNA and HT-1080 cell line with primers \pm (A) HGDNA with wild-type and mutant (181 C>A) primer and (B) HT-1080 cell line with wild-type and mutant (181 C>A) primer (blue: wild-type primer)

\section{Specificity and selectivity of NRAS probes for PNA Clamp QUASAqPCR}

The probes were validated by testing them on cell lines. Probes were selected by adding the wild-type probe with the mutant probes MA and MTG with forward and reverse primers in the presence and absence of PNA. Two probes were designed to amplify the most frequent mutations; MA probe to amplify NRAS c.181C $>$ A (P.Q61K) and MTG to amplify c.182A $>$ T (P.Q61L) and c.182A>G (P.Q61R). A wild-type probe was designed to amplify wild-type allele. In order to check the specificity and selectivity of the probes specific cell lines were used; HT1080 is heterozygous for NRAS c.181C>A (P.Q61K), SK-MEL-2 is heterozygous for NRAS c. 182A $>\mathrm{G}$ (P.Q61R) and IPC-298 is heterozygous for c.182A>T (P.Q61L). In the presence of wild-type probe with MA or MTG probe \pm PNA (Figure 2 A \& C), HGDNA amplified only with wild-type probe; with a $\mathrm{Ct}$ of 30 cycles without PNA and 36 cycles with. PNA shifts the wild-type probe amplification 6 cycles. HT-1080 mutant cell line amplified for wild-type probe -PNA (30 cycles), MA probe PNA (30 cycles) and MA probe +PNA (32 cycles) (Figure $2 \mathrm{~B}$ ). The amplification of the MA probe +PNA was 2 cycles later than the amplification of MA probe -PNA. For MTG probe the amplification for IPC-298 and SKMEL-2 (Figure 2 D\&E) cell lines was unsuccessful \pm PNA as there was no amplification for any of the cell lines. The results of probes specificity lead to the decision to design specific primers for PNA Clamp QUASAqPCR 
Journal of University of Duhok., Vol. 21, No.1(Pure \& Eng. Sciences), Pp 15-36, 2018

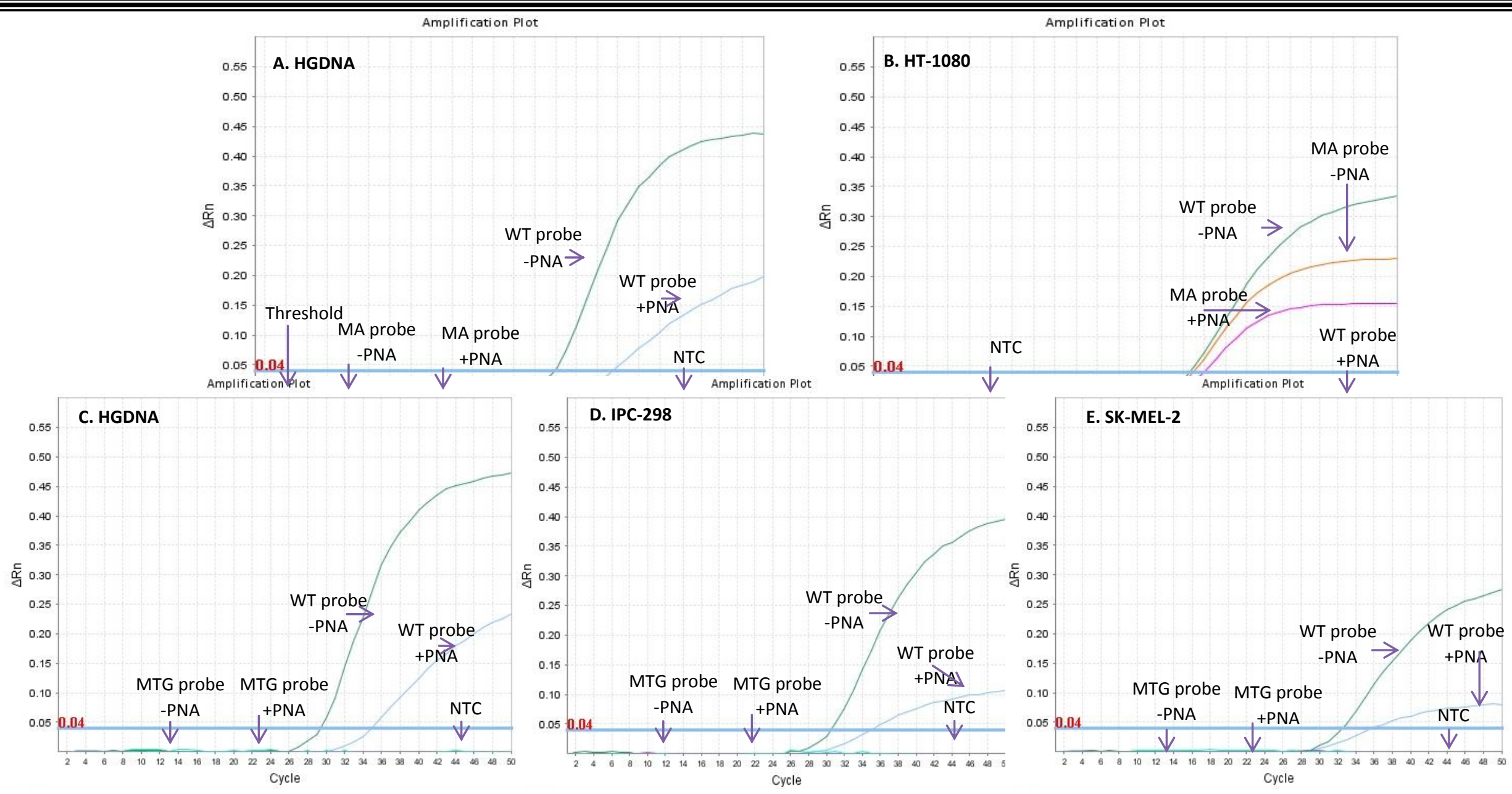

Fig. (2): Specificity and selectivity of $N R A S$ probes for PNA Clamp QUASAqPCR. Wild-type primer with wild-type and mutant MA or MTG probes \pm PNA (A. and C. HGDNA, B. HT-1080, D. IPC-298, E. SK-MEL-2; green: wild-type probe -PNA, blue: wild-type probe +PNA, orange: MA probe -PNA, pink: MA probe +PNA) 


\section{Specificity and selectivity of NRAS primers} for PNA Clamp QUASAqPCR

Forward allele specific mutant primers in combination with NRAS reverse primer, NRAS probe away from mutation and PNA were used to check the specificity of the primers. Four different allele specific primers were used for four different mutations; c.181 C>A (p.Q61K), c.182 A>G (p.Q61R), c.182A>T (P.Q61L) and c.183A>T (P.Q61H). The cell lines used for the primers were HT-1080, IPC-298, SKMEL-2 and RD. The amplification of wild- type primer and allele specific primer (181 C>A) for HGDNA and specific cell line for each allele specific primer is shown in figure 3. HGDNA did not amplify with the mutant primers, HT- 1080 has a Ct of 36 cycles, SKMEL-2 has a Ct of 37 cycles, IPC-298 has $\mathrm{Ct}$ of 37 cycles and RD has a $\mathrm{Ct}$ of 33 cycles and the $\Delta \mathrm{Ct}$ for each cell line was $3,0.2 .3$ and -1 cycles respectively. The amplification of each primer with HGDNA and cell lines is showed in table 6 .

Table 6: Amplification of each primer with HGDNA and cell lines. The table shows the WT Ct mean, mutant $\mathrm{Ct}$ mean and $\Delta \mathrm{Ct}$ of each sample.

\begin{tabular}{|c|c|c|c|c|}
\hline Samples & Primers & $\begin{array}{l}\text { Wild-type primer -PNA Ct } \\
\text { Mean }\end{array}$ & $\begin{array}{l}\text { Mutant primer +PNA } \\
\text { Ct Mean }\end{array}$ & $\Delta \mathrm{Ct}$ \\
\hline \multirow[t]{4}{*}{ HGDNA } & NRAS c.181 C>A (p.Q61K) & 32 & $>50$ & 18 \\
\hline & NRAS c.182 A>G (p.Q61R) & 31 & $>50$ & 19 \\
\hline & NRAS c.182A>T (P.Q61L) & 32 & $>50$ & 19 \\
\hline & NRAS c.183A>T (P.Q61H) & 32 & $>50$ & 18 \\
\hline HT-1080 & NRAS c.181 C>A (p.Q61K) & 38 & $>50$ & 12 \\
\hline SK-MEL-2 & NRAS c.182 A>G (p.Q61R) & 36 & 46 & 14 \\
\hline IPC-298 & NRAS c.182A>T (P.Q61L) & 38 & $>50$ & 12 \\
\hline RD & NRAS c.183A>T (P.Q61H) & 36 & $>50$ & 14 \\
\hline
\end{tabular}

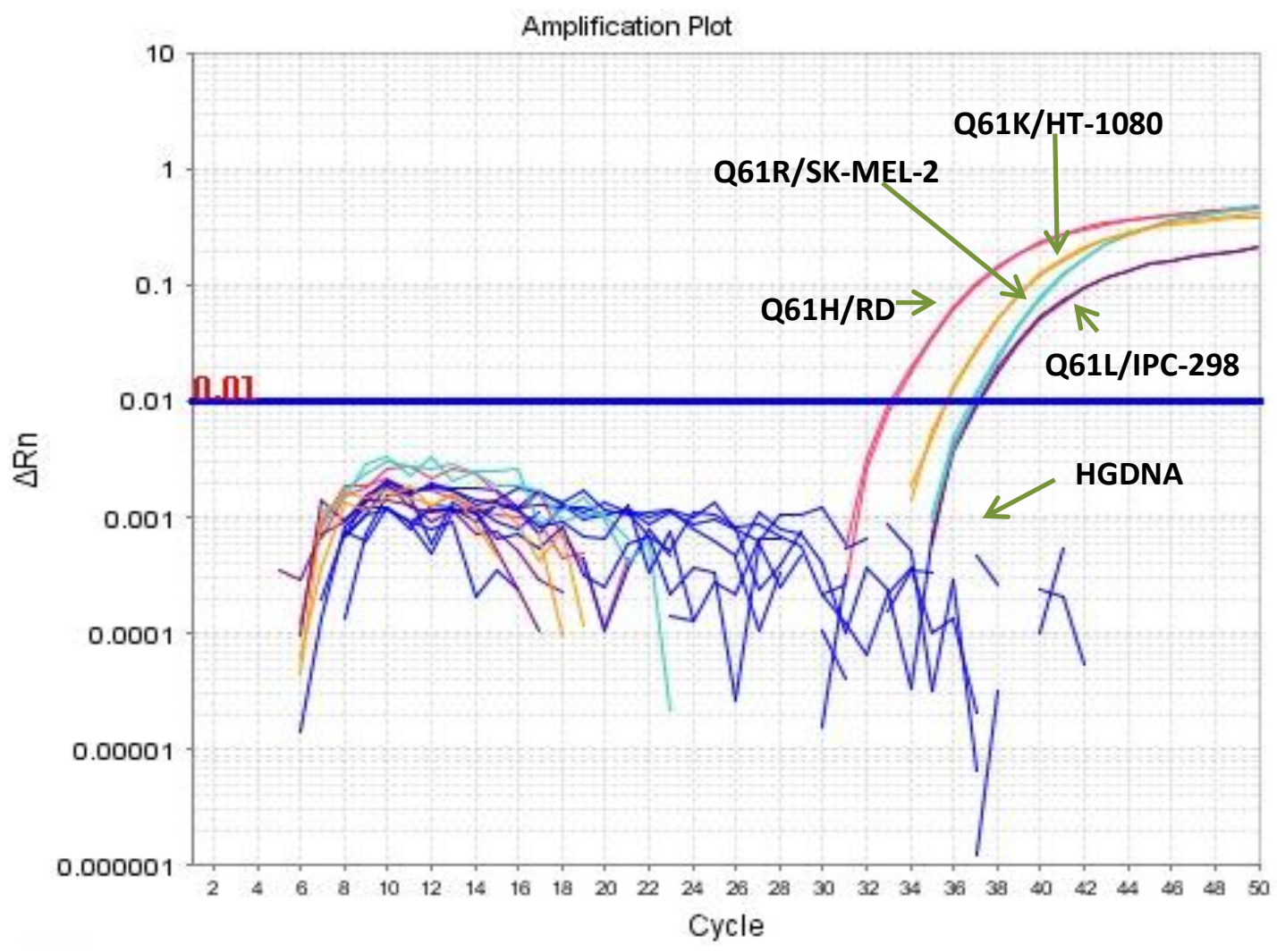

Fig. 3: Specificity and selectivity of $N R A S$ primers for PNA Clamp QUASAqPCR. Amplification plot of the allele specific primers with HGDNA and cell lines (blue: HGDNA, orange: Q61K/HT1080, turquoise: Q61R/SK-MEL-2, purple: Q61L/IPC-298, red: Q61H/RD). 


\section{Analytical sensitivity}

\section{Analytical sensitivity of NRAS PNA Clamp QUASAqPCR}

The analytical sensitivity of the assay was tested by serial dilutions of mutant cell line HT1080 with HGDNA using c.181 C>A (p.Q61K) (Figure 4). The different concentrations of mutated DNA was added to the master mix of mutant primer $181 \mathrm{C}>\mathrm{A}$ in the presence of PNA. The starting concentration was $10 \mathrm{ng} / 3 \mu \mathrm{l}$ of HGDNA with $10 \mathrm{ng} / 3 \mu \mathrm{l}$ of the mutant cell line with dilution factor 1:2. HGDNA was used as reference (wild-type 0\% mutation) and NTC was used as a negative control. All the samples were loaded in triplicates. HGDNA and NTC did not amplify and HT-1080 amplified with a Ct of 35 cycles. All the different concentrations of the mutation started amplifying from 38 to 49 cycles. Mutant DNA with high concentration amplified at earlier cycles and mutant DNA with low concentration amplified at later stage. HGDNA was considered to have a $\mathrm{Ct}$ of 50 cycles as there was no amplification. The $\Delta \mathrm{Ct}$ of mutated DNA compared to WT was different for each concentration. The concentrations and $\Delta \mathrm{Ct}$ of $25 \%, 12.5 \%, 6.25 \%, 3.125 \%, 1.56 \%, 0.78$ $\%, 0.39 \%, 0.18 \%, 0.09 \%, 0.045 \%$ and 0.0245 $\%$ mutated DNA had $\Delta \mathrm{Ct}$ of $13.22,12.54,11.18$, $10.40,9.62,8.21,6.46,5.90,5.63,4.42$ and 3.36 respectively. The assay can detect NRAS codon 61 mutations as low as $0.02 \%$ to $25 \%$ mutation.

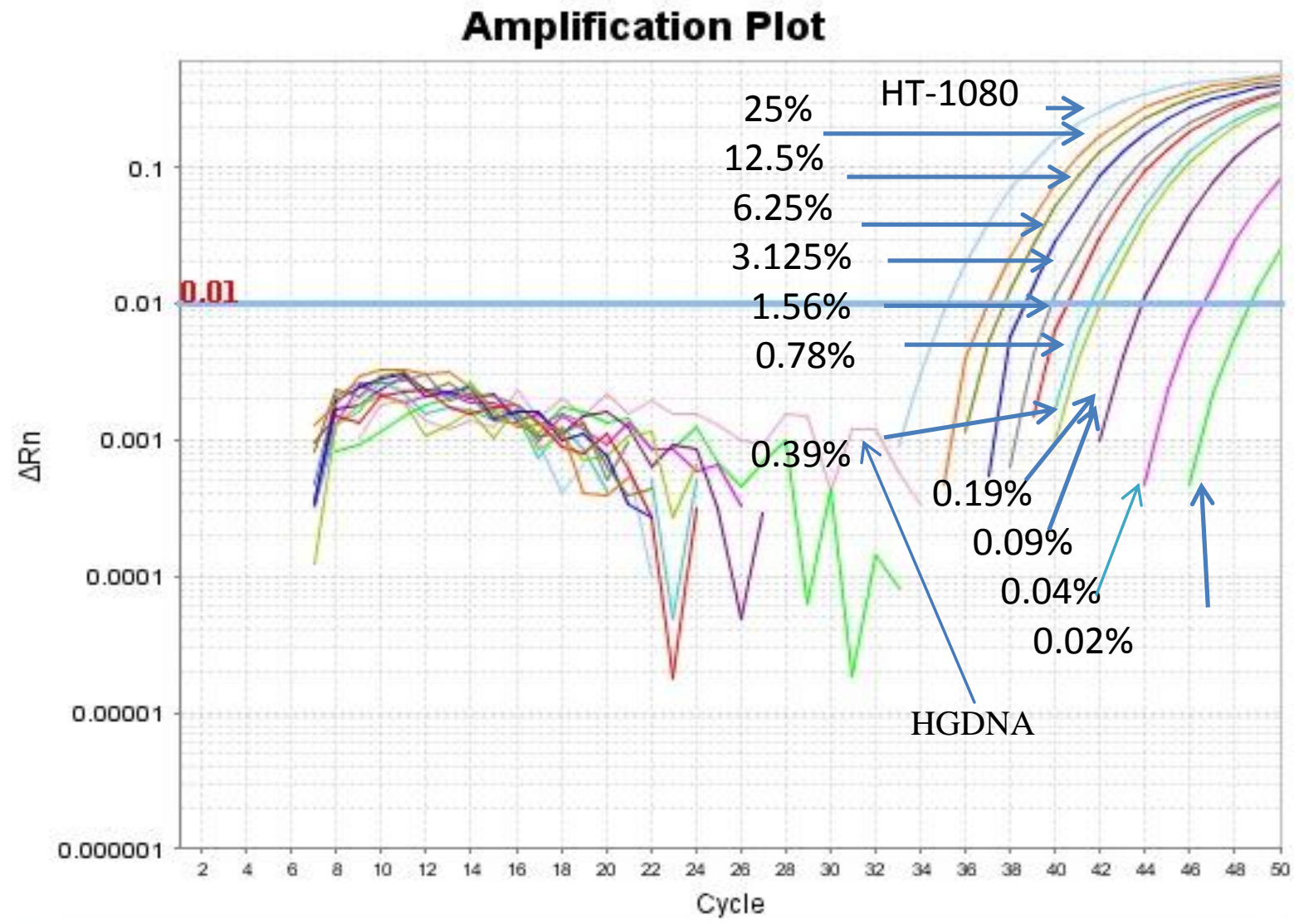

Fig. (4): Analytical sensitivity of NRAS PNA Clamp QUASAqPCR. Amplification plot of serial dilutions

(1:2) of mutant cell line HT-1080 with HGDNA using c.181 C>A (p.Q61K). The mutated DNA percentages were $25 \%, 12.5 \%, 6.25 \%, 3.125 \%, 1.56 \%, 0.78 \%, 0.39 \%, 0.18 \%, 0.09 \%, 0.045 \%$ and $0.0245 \%$. 


\section{Analysis of clinical Samples}

NRAS PNA Clamp QUASAqPCR

For FFPE samples the $\Delta \mathrm{Ct}$ for HT-1080, IPC-298, SK-MEL-2 and RD was 4, 0, 0.2 and -2 cycles respectively. HGDNA had a $\Delta \mathrm{Ct}$ more than 20 cycles as there was no amplification, PNA completely supressed the wild-type. Negative control also did not amplify. With the wild-type primer HGDNA had a $\mathrm{Ct}$ of 32 cycles. Samples that amplified for NRAS were considered as mutated (Figure $5 \mathrm{~A}$ ) and samples that did not amplify were considered as wild type (Figure $5 \mathrm{~B}$ ). 

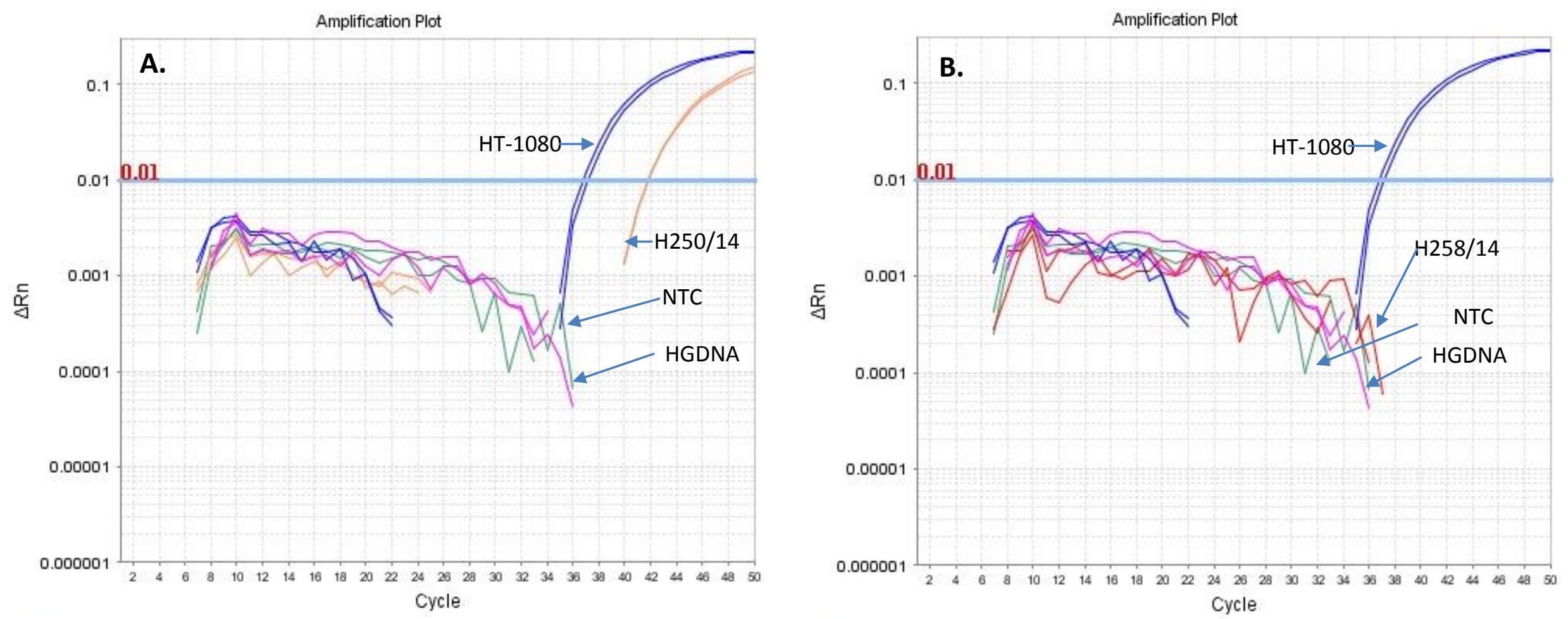

Fig. (5): Amplification plots of FFPE samples using PNA Clamp QUASAqPCR. A) Representation of the HT-1080 cell line amplification (blue) with a $\Delta$ Ct of 37 cycles and a mutated for NRAS sample $\mathrm{H} 250 / 14$ (orange) with a $\triangle \mathrm{Ct}$ of 42 cycles. HGDNA (pink) did not amplify along with the NTC (green). B) Representation of the HT-1080 cell line amplification (blue) with a $\triangle \mathrm{Ct}$ of 37 cycles and a wild-type for NRAS sample H258/14 (red). HGDNA (pink) did not amplify along with the NTC (green). 
For cfDNA samples the $\Delta \mathrm{Ct}$ for HT-1080, IPC-298 and SK-MEL-2 was 5, 4 and 6 cycles respectively. There was no cfDNA left to test for NRAS c.182A $>T$ (P.Q61L) primer. HGDNA had a $\Delta \mathrm{Ct}$ more than 20 cycles as there was no amplification, PNA completely supressed the wild-type. Negative control also did not amplify. With the wild-type primer HGDNA had a Ct of 30 cycles. Samples that amplified for NRAS were considered as mutated (Figure $6 \mathrm{~A}$ ) and samples that did not amplify were considered as $\begin{array}{lllll}\text { wild type (Figure } 6 & \text { B). }\end{array}$

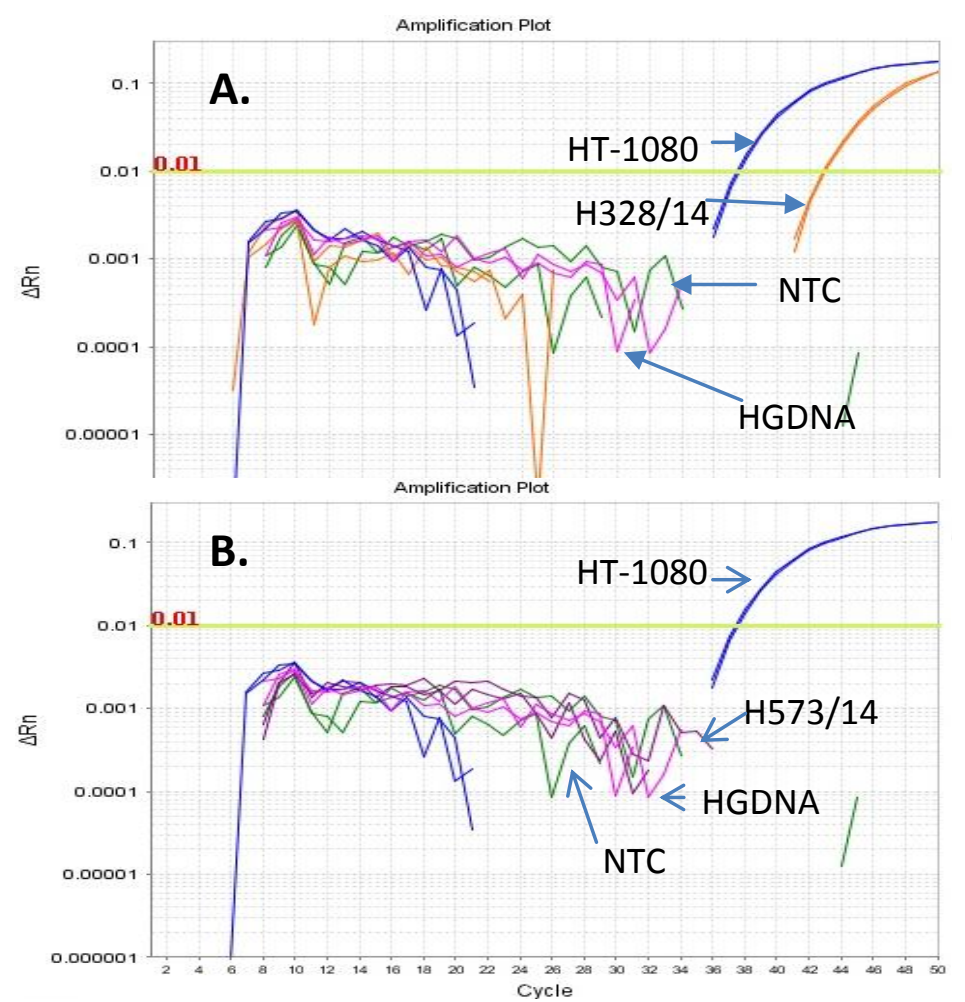

Fig. (6): Amplification plots of cfDNA samples using PNA Clamp QUASAqPCR. A) Representation of the melanoma cell line HT-1080 amplification (blue) with a Ct of 38 cycles and a mutated for NRAS sample H328/14 (orange) with a Ct of 43 cycles. HGDNA (pink) did not amplify along with the NTC (green). B) Representation of the melanoma cell line HT-1080 amplification (blue) with a $\mathrm{Ct}$ of 38 cycles and a wildtype for NRAS sample H573/14 (purple). HGDNA (pink) did not amplify along with the NTC (green).

The status of the cases was again confirmed by plotting the $\Delta \mathrm{Ct}$ (y axis) against the wild-type $\mathrm{Ct}$ ( $\mathrm{x}$ axis). Cases with undetermined mutant $\mathrm{Ct}$ were given a mutant $\mathrm{Ct}$ mean value of 50 cycles in order to calculate the $\Delta \mathrm{Ct}$. Wild-type samples for NRAS had a $\Delta \mathrm{Ct}>10$ cycles. A "cut off"' line, the slope showing the single genome amplification, defining the theoretical limits for detecting mutant alleles (1.6 molecules) was drawn to represent the detectable amount of DNA and determine the status of samples that had single amplification. The line started approximately 10 cycles after the cell line amplification cycle and was parallel to the line formed by samples that appeared to be wildtype. Samples below the line were considered as mutated for the NRAS mutation and samples above the line considered as wild-type tumours for NRAS. Samples very close to the "cut-off" line were considered as wild-type. PNA Clamp QUASAqPCR detected NRAS in 12 out of 48, corresponding to $25 \%$ of the samples (p.Q61K c.181 C>A: 2/48 (4\%); p.Q61L c.182 A>T: $1 / 48$ (2\%); p.Q61R c.182 A>G: 7/48 (15\%); p.Q61K c.183 A>T: $2 / 48(4 \%)$. All the mutated FFPE samples amplified in duplicate (pink). The information for mutated FFPE samples is shown in table 7. cfDNA samples were also tested for the NRAS mutation. PNA Clamp QUASAqPCR detected NRAS in 1 out of 20 samples (H328/14) corresponding to 5\% of the samples (p.Q61K c.181 C>A: 1/20 (5\%); p.Q61L c.182 A>T: 0/20; p.Q61R c.182 A>G: 0/20; p.Q61K c.183 A>T: 0/20) (Figure 7-10). The cfDNA sample that amplified in duplicate had no matched tissue available. The information for mutated cfDNA sample is shown the appendix. For six of the cfDNA samples, matched tissue wasn't available and one of them was mutated for NRAS. None of the remaining 14 matched samples was mutated for NRAS on FFPE tissue. 
NRAS p.Q61K c.181C>A (48 FFPE samples)

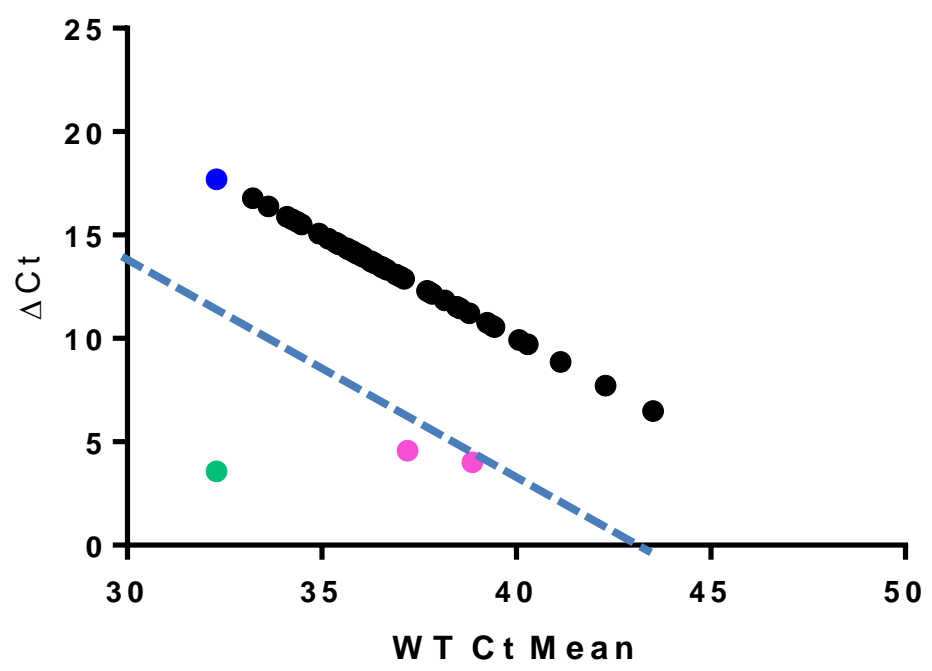

NRAS p.Q61K c.181 C >A (20 cfDNA samples)

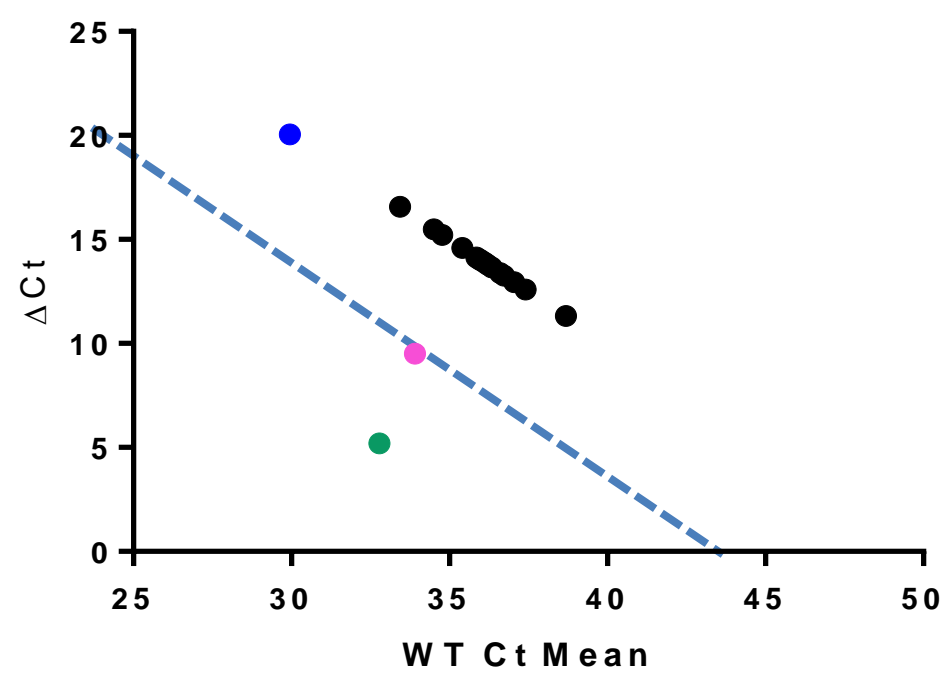

Fig. 7: Plots of NRAS p.Q61K c.181 C>A PNA Clamp QUASAqPCR mutated and wild-type cases for FFPE (n=48) and cfDNA ( $\mathrm{n}=20$ ) samples of wild-type Ct mean with $\Delta$ Ct. Lines represent the "cut off" detectable amount of DNA and determine the status of samples that had single amplification. The line starts $\approx 10$ cycles after cell line $\mathrm{Ct}$ mean cycle. Samples below the line were mutated (pink) and samples above the line are wild-type (black). (FFPE samples: 2 (4\%) mutated and 46 (96\%)

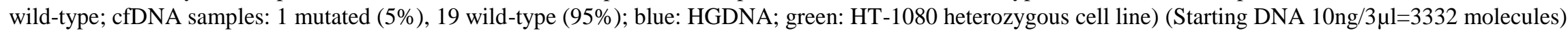


NRAS P.Q61L c.182 A T (48 FFPE samples)

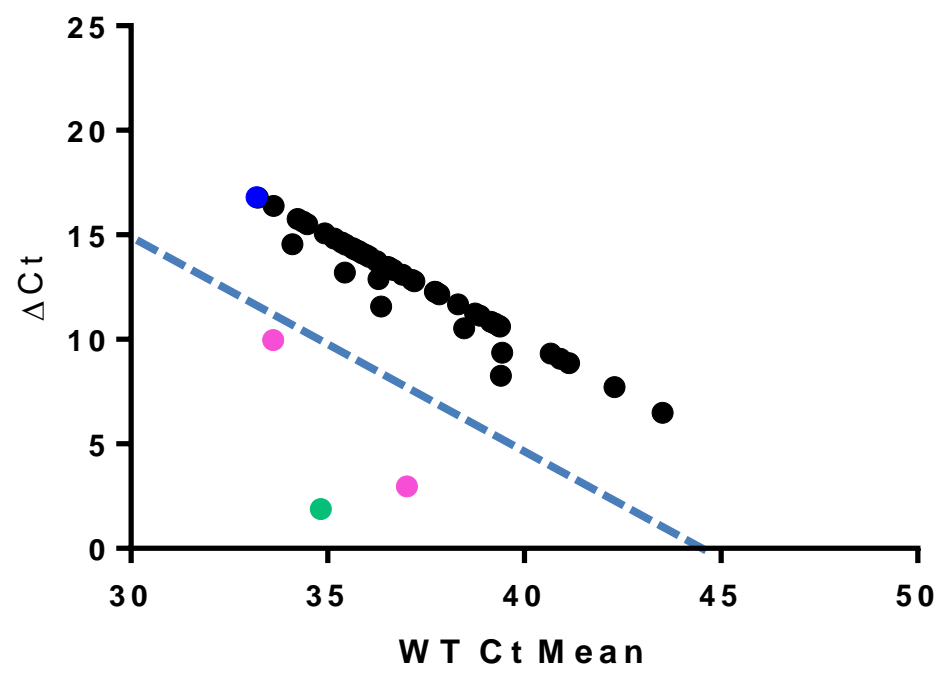

NRAS P.Q61L c.182 A >T (cfDNA)

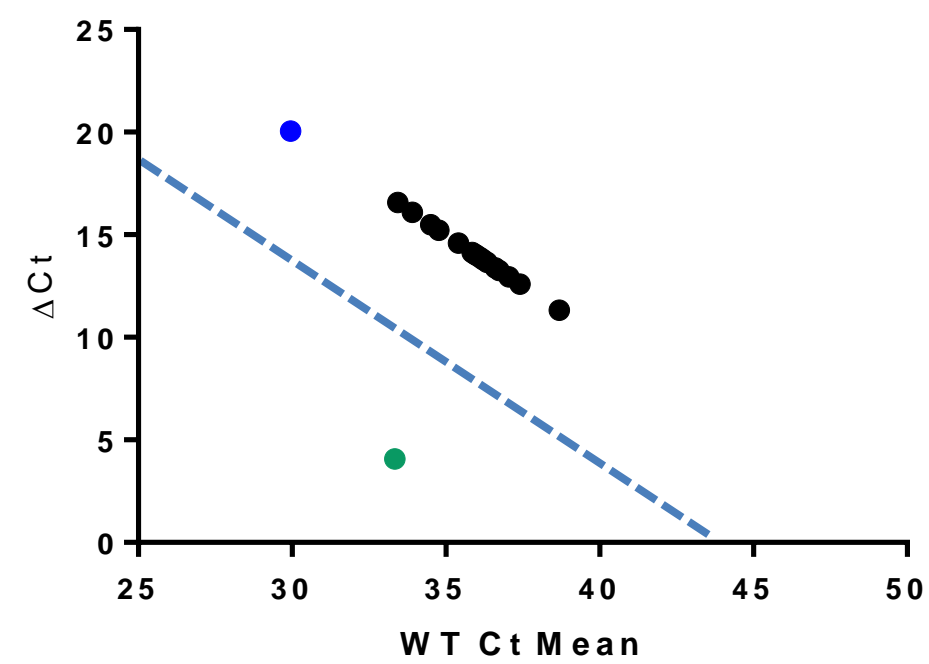

Fig. 8: Plots of NRAS p.Q61L c.182 A>T PNA Clamp QUASAqPCR mutated and wild-type cases for FFPE (n=48) and cfDNA ( $\mathrm{n}=20$ ) samples of wild-type $\mathrm{Ct}$ mean with $\Delta \mathrm{Ct}$. Lines represent the "cut off" detectable amount of DNA and determine the status of samples that had single amplification. Line starts $\approx 10$ cycles after cell line $\mathrm{Ct}$ mean cycle. Samples below the line were mutated (pink) and samples above the line are wild-type (black). (FFPE samples: 1 (2\%) mutated and 47 (98\%) wild-type; cfDNA samples: 20 wild-type (100 \%); blue: HGDNA; green: IPC298 heterozygous cell line) (Starting DNA 10ng/3 $\mu \mathrm{l}=3332$ molecules) 
NRAS p.Q61R c.182 A>G (48 FFPE samples)

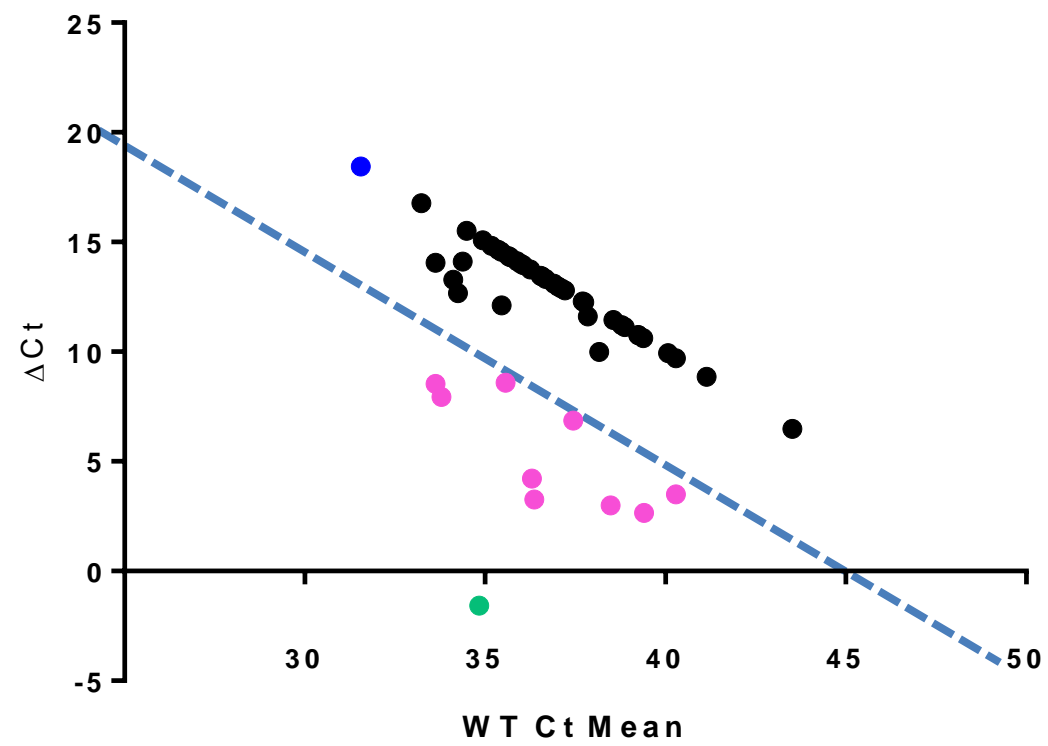

NRAS p.Q61R c.182 A>G (cfDNA)

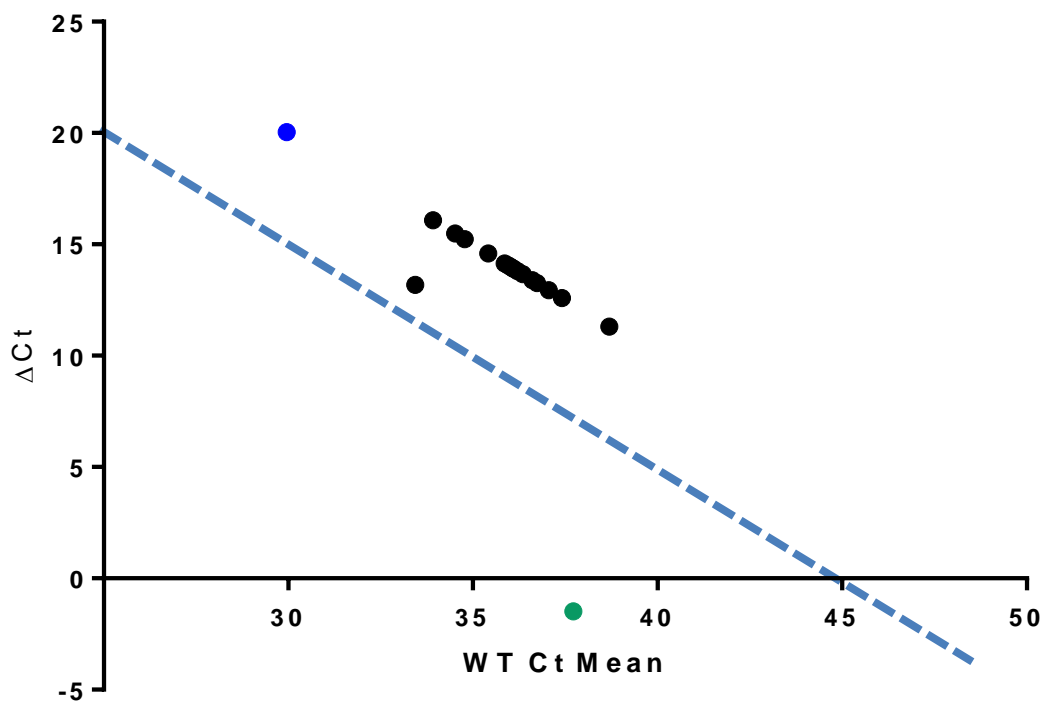

Fig.9: Plots of NRAS p.Q61R c.182 A>G and PNA Clamp QUASAqPCR mutated and wild-type cases for FFPE (n=48) and cfDNA (n=20) samples of wild-type Ct mean with $\Delta$ Ct. Lines represent the "'cut off"' detectable amount of DNA and determine the status of samples that had single amplification. Line starts $\approx 10 \mathrm{cycles}$ after cell line Ct mean cycle. Samples below the line were mutated (pink) and samples above the line are wild-type (black). (FFPE samples: 7 (15\%) mutated and 40 (85\%) wild-type; cfDNA samples: 20 wild-type (10\%); blue: HGDNA; green: SK-MEL-2 heterozygous cell line) (Starting DNA 10ng/3 $\mu$ l=3332 molecules) 


\section{NRASP.Q61H C.183 A>T (48 FFPE samples)}

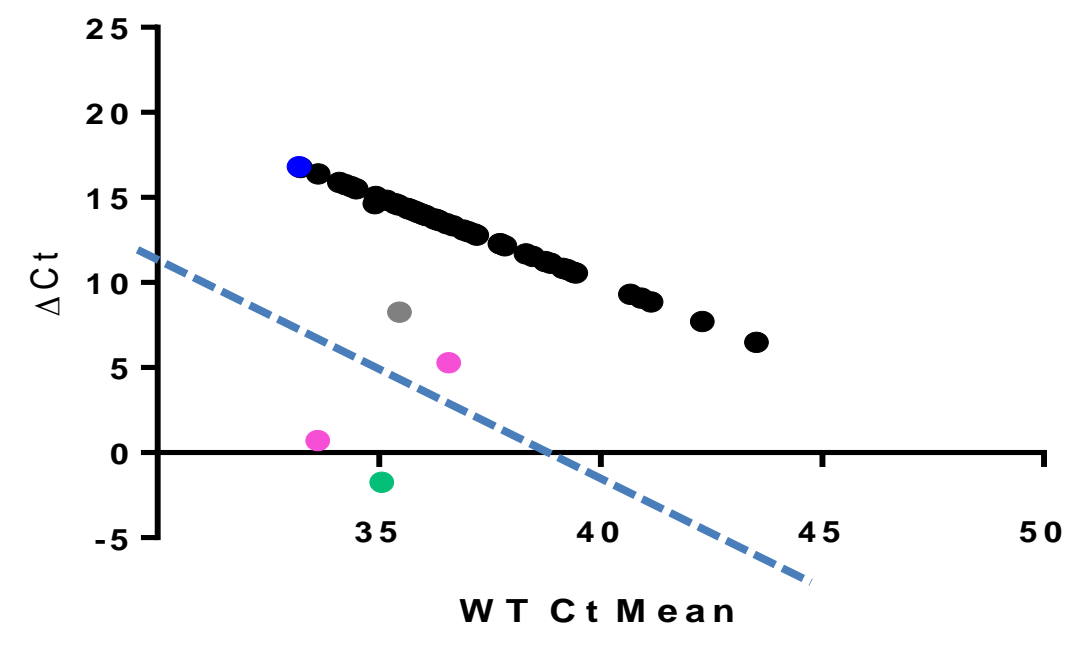

Fig.10: Plots of NRAS p.Q61H c.183 A>T and PNA Clamp QUASAqPCR mutated and wild-type cases for FFPE (n=48) samples of wild-type Ct mean with $\Delta \mathrm{Ct}$. Lines represent the "cut off' detectable amount of DNA and determine the status of samples that had single amplification. Line starts $\approx 10$ cycles after cell line $\mathrm{Ct}$ mean cycle. Samples below the line were mutated (pink) and samples above the line are wild-type (black). (FFPE samples: 2 (4\%) mutated and $46(96 \%)$ wild-type; blue: HGDNA; green: RD heterozygous cell lines, grey: single amplification)

(Starting

DNA

$10 \mathrm{ng} / 3 \mu \mathrm{l}=3332$ molecules) 
Table 7: NRAS codon 61 PNA Clamp QUASAqPCR information for mutated FFPE samples.

\begin{tabular}{|c|c|c|c|c|}
\hline FFPE Block no & Mutation & $\underline{\text { WT Ct }}$ & MUT Ct & $\underline{\Delta C t}$ \\
\hline $\mathrm{H} 241 / 14$ & p.Q61R c.182 A>G & 42.290 & 45.790 & 3.500 \\
\hline $\mathrm{H} 243 / 14$ & p.Q61K c.181 C>A & 38.867 & 42.877 & 4.010 \\
\hline $\mathrm{H} 246 / 14$ & p.Q61R c.182 A>G & 39.444 & 46.307 & 6.863 \\
\hline $\mathrm{H} 249 / 14$ & p.Q61R c.182 A>G & 38.871 & 39.159 & 0.289 \\
\hline $\mathrm{H} 250 / 14$ & p.Q61K c.181 C>A & 37.211 & 41.787 & 4.576 \\
\hline $\mathrm{H} 254 / 14$ & p.Q61R c.182 A>G & 36.295 & 40.513 & 4.218 \\
\hline $\mathrm{H} 256 / 14$ & p.Q61R c.182 A>G & 35.790 & 45.736 & 9.946 \\
\hline $\mathrm{H} 259 / 14$ & p.Q61L c.182 A>T & 37.020 & 39.985 & 2.965 \\
\hline $\mathrm{H} 261 / 14$ & p.Q61H c.183 A>T & 36.575 & 41.856 & 5.281 \\
\hline $\mathrm{H} 262 / 14$ & p.Q61R c.182 A>G & 38.471 & 41.472 & 3.000 \\
\hline $\mathrm{H} 271 / 14$ & p.Q61R c.182 A>G & 36.363 & 39.628 & 3.265 \\
\hline $\mathrm{H} 276 / 14$ & p.Q61H c.183 A>T & 33.620 & 34.329 & 0.709 \\
\hline
\end{tabular}

Patients stage and concentration of cfDNA

The concentration of cfNDA varied from $0.003-0.533 \mathrm{ng} / 3 \mu \mathrm{L}$. The patients' stage ranged from stage II-IV; fifteen samples were stage IV, two stage III, one stage II and two patients that had tumour excision. The information for the stage and cfDNA concentration of each samples in shown in table 8 .

Table 8: Patient's stage and concentration of cfDNA $(n g / 3 \mu L)$

\begin{tabular}{lll}
\hline cfDNA no & Stage & {$[\mathrm{cfDNA}]$} \\
\hline $\mathrm{H} 337 / 14$ & Metastatic & 0.011 \\
\hline $\mathrm{H} 338 / 14$ & Metastatic & 0.003 \\
\hline $\mathrm{H} 336 / 14$ & Metastatic & 0.007 \\
\hline $\mathrm{H} 328 / 14$ & Metastatic & 0.056 \\
\hline $\mathrm{H} 631 / 13$ & Metastatic & 0.003 \\
\hline $\mathrm{H} 573 / 13$ & Metastatic & 0.003 \\
\hline $\mathrm{H} 346 / 14$ & IIIC & 0.003 \\
\hline $\mathrm{H} 493 / 14$ & IIIB & 0.022 \\
\hline $\mathrm{H} 378 / 14$ & Metastatic & 0.054 \\
\hline $\mathrm{H} 335 / 14$ & no res. tumour & 0.17 \\
\hline $\mathrm{H} 348 / 14$ & Metastatic & 0.075 \\
\hline $\mathrm{H} 347 / 14$ & Metastatic & 0.059 \\
\hline $\mathrm{H} 327 / 14$ & no res. tumour & 0.088 \\
\hline $\mathrm{H} 669 / 13$ & Metastatic & 0.041 \\
\hline $\mathrm{H} 668 / 13$ & Metastatic & 0.138 \\
\hline & & \\
\hline & & \\
\hline & & \\
\hline
\end{tabular}

*E-mail: riger.romi@uod.ac 


\begin{tabular}{lll}
\hline $\mathrm{H} 492 / 13$ & Metastatic & 0.115 \\
\hline $\mathrm{H} 1707 / 12$ & Metastatic & 0.533 \\
\hline $\mathrm{H} 1436 / 12$ & $\mathrm{IIC}$ & 0.131 \\
\hline $\mathrm{H} 391 / 14$ & Metastatic & 0.087 \\
\hline $\mathrm{H} 392 / 14$ & Metastatic & 0.238 \\
\hline
\end{tabular}

Information on clinical samples

A number of 14 cfDNA samples were available that matched FFPE tissue that were already analysed with qPCR (6 BRAF FFPE and cfDNA +ve, 4 BRAF FFPE +ve, 1 NRAS FFPE and cfDNA +ve, 3 ve). Information for the cases is shown in table 9.

Table 9: Matched FFPE tissue with cfDNA samples

\begin{tabular}{|c|c|c|c|c|}
\hline FFPE Block no. & cfDNA no. & $\begin{array}{l}\text { FFPE } \\
\text { tissue }\end{array}$ & cfDNA & Comments \\
\hline & & NRAS & NRAS & \\
\hline $\mathrm{H} 242 / 14$ & H347/14 & -ve & -ve & $! !$ \\
\hline $\mathrm{H} 244 / 14$ & $\mathrm{H} 573 / 13$ & -ve & -ve & - \\
\hline H249/14 & $\mathrm{H} 493 / 14$ & $\begin{array}{l}+\mathrm{Ve} \\
\mathrm{Q} 61 \mathrm{~K}\end{array}$ & -ve & !! \\
\hline $\mathrm{H} 251 / 14$ & $\mathrm{H} 668 / 13$ & -ve & -ve & !! \\
\hline H272/14 & $\mathrm{H} 631 / 13$ & -ve & -ve & - \\
\hline H275/14 & $\mathrm{H} 327 / 14$ & -ve & -ve & $\begin{array}{l}\text { Previous metastatic disease, but all metastases excised. } \\
\text { No residual tumour. }\end{array}$ \\
\hline H398/14 & $\mathrm{H} 338 / 14$ & -ve & -ve & Previous BRAF inhibitor \\
\hline H399/14 & $\mathrm{H} 337 / 14$ & -ve & -ve & Previous BRAF inhibitor stopped due to toxicity \\
\hline H400/14 & $\mathrm{H} 378 / 14$ & -ve & -ve & !! \\
\hline H403/14 & $\mathrm{H} 1436 / 14$ & -ve & -ve & no information about treatment \\
\hline H404/14 & $\mathrm{H} 492 / 13$ & -ve & - -ve & BRAF inhibitor after blood taken \\
\hline H406/14 & $\mathrm{H} 669 / 14$ & -ve & -ve & $\begin{array}{l}\text { Previous metastatic disease, but all metastases excised. } \\
\text { No residual tumour. }\end{array}$ \\
\hline $\mathrm{H} 407 / 14$ & $\mathrm{H} 1707 / 14$ & -ve & -ve & !! \\
\hline $\mathrm{H} 409 / 14$ & $\mathrm{H} 348 / 14$ & -ve & -ve & !! \\
\hline
\end{tabular}

\section{DISCUSSION}

The qPCR was used to detect point mutations in NRAS gene. Primers and probes were designed to extend and amplify the target. 50 cycles were used in TD method as it increases the number of cycles by 10-15. . However, primers were used in QUASAqPCR as probes were not specific in order to be used. The most specific primer was NRAS p.Q61K (c.181C>A) with $\Delta \mathrm{Ct}$ of 2 cycles. TD method was used to increase the specificity and sensitivity of PCR amplification. The starting annealing temperature for the first cycle phase was higher than primers $\mathrm{Tm}$ by $10^{\circ} \mathrm{C}\left(69^{\circ} \mathrm{C}\right)$ and then decreased by $1{ }^{\circ} \mathrm{C}$ every cycle until it reached the primers Tm (Kramer M. et al., 2001). 50 cycles were used in TD method as it increases the number of cycles by 10-15. TD method was used to increase the specificity and sensitivity of PCR amplification. The starting annealing temperature for the first cycle phase was higher than primers $\mathrm{Tm}$ by $10^{\circ} \mathrm{C}\left(69^{\circ} \mathrm{C}\right)$ and then decreased by $1^{\circ} \mathrm{C}$ every cycle until it reached the primers Tm (Kramer M. et al., 2001). Two of the most common mutation detections methods are DNA sequencing and restriction fragment length polymorphism (RFLP) (Murdock D. et al., 2002). However, according to Murdock et al. (2002), PNA PCR clamping is a sensitive 
method that can identify nucleotide changes in DNA molecules, even in a small fraction of the total DNA (Murdock D. et al., 2002). In this project, PNA was used to block the wild-type amplification while allowing the mutant to amplify. PNA sensitivity, specificity and selectivity were first validated on cell lines known to carry specific mutations of NRAS codon 61. PNA was found to be very specific as it completely suppressed the wild type amplification in mutant reactions. All the samples were analysed by PNA Clamp QUASAqPCR and the status of each sample was determined by the amplification of each sample as before. Samples were determined as mutant when tested with mutant allele and there was amplification in duplicate. If there was no amplification samples were considered as wild type, negative for NRAS mutation. A "cut off" line, the slope showing the single genome amplification, defining the theoretical limits for detecting mutant alleles (1.6 molecules) was drawn to represent the detectable amount of DNA and determine the status of samples that had single amplification. Samples below the line were considered as mutated for the NRAS mutations and samples above the line considered as wild-type tumours for NRAS.

The frequency of each mutation was obtained from COSMIC. In malignant melanoma NRAS mutation frequency is $17 \%$ and among the mutations in NRAS 34\% is Q61K mutation, 35\% is $\mathrm{Q} 61 \mathrm{R}$ mutations, 8\% Q61L mutation, $1 \%$ Q61H mutation and few other mutations with lower frequency. However, in this project PNA Clamp QUASAqPCR detected NRAS in 12 out of 48 FFPE tissue samples, corresponding to $25 \%$. Among these $25 \%$ were p.Q61K c.181 C>A: $16 / 48$ (4\%); p.Q61L c.182 A>T: $1 / 48$ (8\%); p.Q61R c.182 A>G: 7/48 (60\%); p.Q61K c.183 A>T: $2 / 48$ (16\%). In cfDNA PNA Clamp QUASAqPCR detected NRAS in 1 out of 20 corresponding to $5 \%$ of the samples with Q61K mutation. In addition according to Carlino et al. (2014), in a study of 193 patients $20 \%$ harbour NRAS mutation of which $85 \%$ were substitutions for glutamine at position 61(Carlino M. et al., 2014). The $R A S / R A F / M E K / E R K$ signalling kinase cascade is constantly active in melanoma due to mutations in BRAF or NRAS (Sebolt-Leopard J. et al., 2004).

The use of FFPE tissue from biopsies is essential for immunohistochemistry and haematoxylin and eosin staining but has several arising issues when is used with molecular methods such as qPCR. First of all, cross-linking is caused by formaldehyde which covalently links nucleic acids resulting is lower efficiency of molecules in qPCR (Perkel, 2014). Moreover, in cancer patients when the position of the tumour is difficult to perform biopsy, for example in lung cancer patients, the tumour material is inadequate (Sequist L. et al., 2009). In addition, the amount of tumour in FFPE tissue is low as it is mixed with normal tissue (Plesec T. et al., 2009). According to Fleischhacker et al. (2008) and Gerlinger et al., (2012), biopsies are taken from a part of the tumour arising the issue if all the mutant clones are included in tumour heterogeneity; leading to the conclusion that the specificity and sensitivity of qPCR is greatly affected as there are chemical changes in DNA and low number of molecules, resulting in higher $\mathrm{Ct}$ signalling Fleischhacker $e t$ al. (2008) and Gerlinger et al., (2012). On the other hand, cfDNA in qPCR might be a better biomarker as it is not formalin fixed and less non-specific binding should be observed resulting in an increase of the sensitivity and the specificity (Aung K. et al., 2014). According to a study by Board et al. (2008), cfDNA can be extracted by both plasma and serum with serum having the disadvantage of white blood cells (Board R. et al., 2008). The results shows that, only one case was NRAS Q61R positive in FFPE tissue and three cases were negative. On a final note, the results of this study showed that PNA Clamp PCR methods could be very sensitive and specific for mutation detection. Moreover, the use of cfDNA mutation testing could be used as an initial screening step to determine the patients with NRAS mutant tumours for clinical trials which will be very beneficial as more patients with metastatic disease will be identified earlier which will therefore improve efficiency of future clinical trials. In addition, this method will be very useful in cases where biopsy is difficult to be performed.

\section{REFERENCES}

- Aung, K.L., Donald, E., Ellison, G., Bujac, S., Fletcher, L., Cantarini, M., et al, 2014. Analytical validation of BRAF mutation testing from circulating free DNA using the amplification refractory mutation testing system. The Journal of Molecular Diagnostics, 16(3), pp.343-349. 
- Board, R.E., Williams, V.S., Knight, L., Shaw, J., Greystoke, A., Ranson, M., et al , 2008. Isolation and extraction of circulating tumor DNA from patients with small cell lung cancer. Annals of the New York Academy of Sciences, 1137(1), pp.98-107.

- Cancer.org, (2014). What are the survival rates for melanoma skin cancer by stage?. [online] Available at: http://www.cancer.org/cancer/skincancermelanoma/detailedguide/melanoma-skincancer-survival-rates [Accessed 16 Jul. 2014].

- Cancer.sanger.ac.uk, (2014). COSMIC: Tissue browser. [online] Available at: http://cancer.sanger.ac.uk/cosmic/browse/ tissue\#sn=skin \&ss=all\&hn=malignant_m elanoma $\&$ sh $=$ all $\&$ in $=$ t $\&$ src $=$ tissue [Accessed 31 May. 2014].

- Cancerresearchuk.org, (2014). Melanoma skin cancer: Cancer Research UK : CancerHelp UK. [online] Available at: http://www.cancerresearchuk.org/cancerhelp/type/melanoma/ [Accessed 4 April. 2014].

- Chapman, P.B., Hauschild, A., Robert, C., Haanen, J.B., Ascierto, P., Larkin, J. et al, 2011. Improved survival with vemurafenib in melanoma with BRAF V600E mutation. New England Journal of Medicine, 364(26), pp.2507-2516.

- Flaherty, K.T., Hodi, F.S. and Fisher, D.E., 2012. From genes to drugs: targeted strategies for melanoma. Nature Reviews Cancer, 12(5), p.349.

- Garcia-Olmo, D.C., Ruiz-Piqueras, R. and Garcia-Olmo, D., 2004. Circulating nucleic acids in plasma and serum (CNAPS) and its relation to stem cells and cancer metastasis: state of the issue. Histology and histopathology, 19(2), pp.575-583.

- Gerlinger, M., Rowan, A.J., Horswell, S., Larkin, J., Endesfelder, D., Gronroos, E., et al, 2012. Intratumor heterogeneity and branched evolution revealed by multiregion sequencing. New England journal of medicine, 366(10), pp.883-892.
- Jakob, J.A., Bassett, R.L., Ng, C.S., Curry, J.L., Joseph, R.W., Alvarado, G.C., et al, 2012. NRAS mutation status is an independent prognostic factor in metastatic melanoma. Cancer, 118(16), pp.4014-4023.

- Kramer, M.F. and Coen, D.M., 2001. Enzymatic amplification of DNA by PCR: standard procedures and optimization. Current protocols in toxicology, pp.A-3C.

-Lyon, E. and Wittwer, C.T., 2009. LightCycler technology in molecular diagnostics. The Journal of Molecular Diagnostics, 11(2), pp.93-101.

- Murdock, D.G. and Wallace, D.C., 2002. PNA-mediated PCR clamping. In Peptide Nucleic Acids (pp. 145-164). Springer, Totowa, NJ.

- Omholt, K., Platz, A., Kanter, L., Ringborg, U. and Hansson, J., 2003. NRAS and BRAF mutations arise early during melanoma pathogenesis and are preserved throughout tumor progression. Clinical Cancer Research, 9(17), pp.6483-6488.

- Perkel, J. (2014). Working with FFPE Tissue | Biocompare Editorial Article. [online] Biocompare.com. Available at: http://www.biocompare.com/EditorialArticles/41751-Working-with-FFPETissue/ [Accessed 27 Jul. 2014].

- Plesec, T.P. and Hunt, J.L., 2009. KRAS mutation testing in colorectal cancer. Advances in anatomic pathology, 16(4), pp.196-203.

- Posch, C. and Ortiz-Urda, S., 2013. NRAS mutant melanomaundrugable?. Oncotarget, 4(4), p.494.

- Sebolt-Leopold, J.S. and English, J.M., 2006. Mechanisms of drug inhibition of signalling molecules. Nature, 441(7092), p. 457 .

- Sequist, L.V., Engelman, J.A. and Lynch, T.J., 2009. Toward noninvasive genomic screening of lung cancer patients.

- Swick, J.M. and Maize, J.C., 2012. Molecular biology of melanoma. Journal of the American Academy of Dermatology, 67(5), pp.1049-1054. 